\title{
Screening for GPR101 defects in pediatric pituitary corticotropinomas
}

\author{
Giampaolo Trivellin',*, Ricardo R Correa ${ }^{1,2, *}$, Maria Batsis'1,2, Fabio R Faucz', \\ Prashant Chittiboina3, Ivana Bjelobaba4, Darwin O Larco5, Martha Quezado6, \\ Adrian F Daly7, Stanko S Stojilkovic4, T John Wu5, Albert Beckers7, Maya B Lodish1,2 \\ and Constantine A Stratakis ${ }^{1,2}$
}

\author{
1Section on Endocrinology and Genetics, Eunice Kennedy Shriver National Institute of Child Health and \\ Human Development (NICHD), National Institutes of Health (NIH), Bethesda, Maryland, USA \\ 2Endocrinology Training Programs, Eunice Kennedy Shriver National Institute of Child Health and \\ Human Development (NICHD), National Institutes of Health (NIH), Bethesda, Maryland, USA \\ ${ }^{3}$ Surgical Neurology Branch, National Institute of Neurological Diseases and Stroke (NINDS), \\ National Institutes of Health (NIH), Bethesda, Maryland, USA \\ 4Section on Cellular Signaling, Eunice Kennedy Shriver National Institute of Child Health and Human \\ Development (NICHD), National Institutes of Health (NIH), Bethesda, Maryland, USA \\ ${ }^{5}$ Department of Obstetrics and Gynecology, Uniformed Services University of the Health Sciences, \\ Bethesda, Maryland, USA \\ ${ }^{6}$ Laboratory of Pathology, National Cancer Institute (NCl), National Institutes of Health (NIH), Bethesda, \\ Maryland, USA \\ 7Department of Endocrinology and Clinical Genetics, Centre Hospitalier Universitaire de Liège, \\ University of Liège, Domaine Universitaire du Sart-Tilman, Liège, Belgium \\ *(G Trivellin and R R Correa contributed equally to this work)
}

Correspondence should be addressed to C A Stratakis Email stratakc@mail.nih.gov

\begin{abstract}
Cushing's disease (CD) in children is caused by adrenocorticotropic hormone (ACTH)-secreting pituitary adenomas. Germline or somatic mutations in genes such as MEN1, CDKIS, AIP, and USP8 have been identified in pediatric CD, but the genetic defects in a significant percentage of cases are still unknown. In this study, we investigated the orphan G-protein-coupled receptor GPR101, a gene known to be involved in somatotropinomas, for its possible involvement in corticotropinomas. We performed GPR101 sequencing, expression analyses by RT-qPCR and immunostaining, and functional studies (cell proliferation, pituitary hormone secretion, and cAMP measurement) in a series of patients with sporadic CD secondary to ACTH-secreting adenomas in whom we extracted DNA from peripheral blood and pituitary tumor samples $(n=36)$. No increased GPR101 expression was observed in tumors compared with normal pituitary (NP) tissues, nor did we find a correlation between GPR101 and ACTH expression levels. Sequence analysis revealed a very rare germline heterozygous GPR101 variant (p.G31S) in one patient with CD. Overexpression of the p.G31S variant did not lead to increased growth and proliferation, although modest effects on CAMP signaling were observed. GPR101 is not overexpressed in ACTH-secreting tumors compared with NPs. In conclusion, rare germline GPR101 variant was found in one patient with $C D$, but in vitro studies did not support a consistent pathogenic effect. GPR101 is unlikely to be involved in the pathogenesis of CD.
\end{abstract}

\author{
Key Words \\ - GPR101 \\ - Cushing's disease \\ - ACTH-secreting adenomas
}




\section{Introduction}

Cushing's disease (CD) affects approximately $70 \%$ of patients with endogenous Cushing's syndrome (Tritos \& Biller 2014). CD is caused by adrenocorticotropic hormone (ACTH)-secreting pituitary adenomas (corticotropinomas) (Newell-Price 2009). Although germline mutations in genes such as MEN1, CDKIs, and AIP, and somatic mutations in USP8 have been identified in patients with $\mathrm{CD}$, for many corticotropinomas the molecular pathways involved in their pathogenesis remain unknown (Stratakis et al. 2010, Reincke et al. 2015).

We have recently found that the GPR101 gene is involved in the pathogenesis of pituitary growth hormone (GH)-secreting adenomas (Trivellin et al. 2014, Beckers et al. 2015). GPR101 encodes an orphan G protein-coupled receptor that is highly expressed in the hypothalamus, where it may play a role in the hypothalamic control of energy homeostasis and pituitary hormone secretion (Lee et al. 2001, Bates et al. 2006, Nilaweera et al. 2007, 2008, Regard et al. 2008, Trivellin et al. 2014). GPR101 is also highly expressed in the GH-secreting pituitary tumors of patients with X-linked acrogigantism caused by GPR101 duplication, whereas it is expressed at low levels in normal pituitary (NP) tissue and in non-GPR101 duplicated somatotropinomas (Trivellin et al. 2014). The mechanism(s) by which GPR101 might increase pituitary hormones secretion remain unclear at present, although the possible involvement of GHRH has been shown (Beckers et al. 2015, Daly et al. 2016). Previous studies from our and other groups support the idea that GPR101 can strongly activate the cAMP pathway (Trivellin et al. 2014, Bates et al. 2006), whose mitogenic effects in pituitary cells are well established (Peverelli et al. 2014).

In this study, we investigated the possible involvement of GPR101 in CD by performing GPR101 sequencing, expression analyses, and functional studies in a series of sporadic ACTH-secreting adenomas. We further report a case associated with a very rare missense variant (p.G31S).

\section{Subjects and methods}

\section{Subjects}

A series of 36 patients with $\mathrm{CD}$ corroborated by biochemical testing and pathology positive for ACTH staining in pituitary adenomas were analyzed. These patients were selected because of the availability of tumor and peripheral DNA samples. Testing for germline mutations/deletions in genes associated with pituitary adenomas (AIP, MEN1) was performed and no defects were observed. Patients harboring a USP8 mutation at the tumor DNA level were also excluded from this analysis (data not shown). The Eunice Kennedy Shriver National Institute of Child Health and Human Development Institutional Review Board approved this study, and informed consent was obtained from all the patients.

\section{Sequencing analysis}

DNA was extracted from peripheral blood and pituitary tumor samples using the QIAamp DNA Mini Kit (Qiagen) according to the manufacturer's protocols. The whole coding region of GPR101 was PCR amplified and directly sequenced. The following primers were used: GPR101_1AF: ACTGAGCCTGCAACCTGTCT; GPR101_1AR: TCCACTG ACACCACGACAAT; GPR101_1BF: TTAGCCTCACCCAC CTGTTC; GPR101_1BR: CTTCCTTCCTTGGCCTTCAG; GPR101_1CF: CAGCATGAAGGTGAGGTCAA; GPR101_ 1CR: CCCAGGGATAGCACATAGGA; GPR101_1DF: GTGC TACCAGTGCAAAGCTG; GPR101_1DR: TGAATTGTGGG TCCATTGAA. DNA sequencing was performed using the BigDye 3.1 termination chemistry (Applied Biosystems) on a Genetic Sequencer ABI 3500XL apparatus (Applied Biosystems). Sequences were visualized and aligned to the corresponding wild-type (WT) reference sequence using SeqMan Pro software (DNASTAR, Madison, Wisconsin, USA). All variants have been annotated according to Human Genome Variation Society recommendations (www.hgvs.org/mutnomen). The NM_054021.1 reference sequence was used to annotate GPR101 variants.

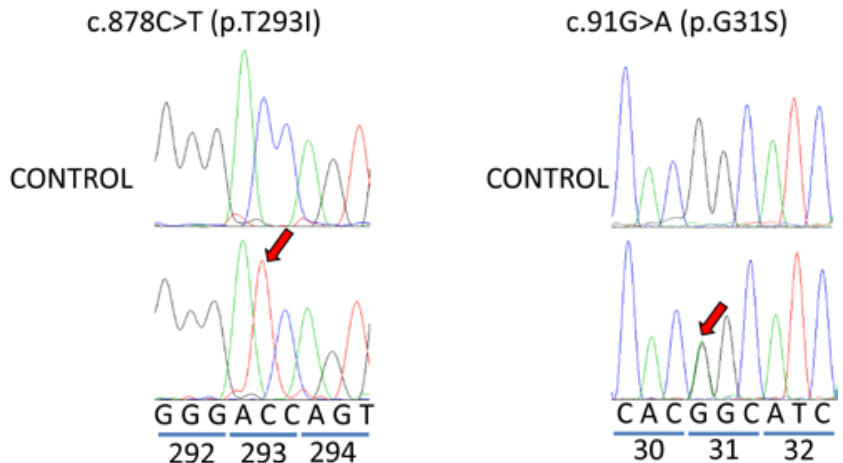

Figure 1

DNA sequence chromatograms showing the position of two GPR101 variants found in our patients. The homozygous $\mathrm{p}$.T293I variant is shown on the left side, whereas the heterozygous p.G31S variant on the right side. The location of each nucleotide change is indicated by a red arrow. Below each chromatogram, the WT nucleotide sequence and the corresponding codon numbers are reported.

Published by Bioscientifica Ltd 


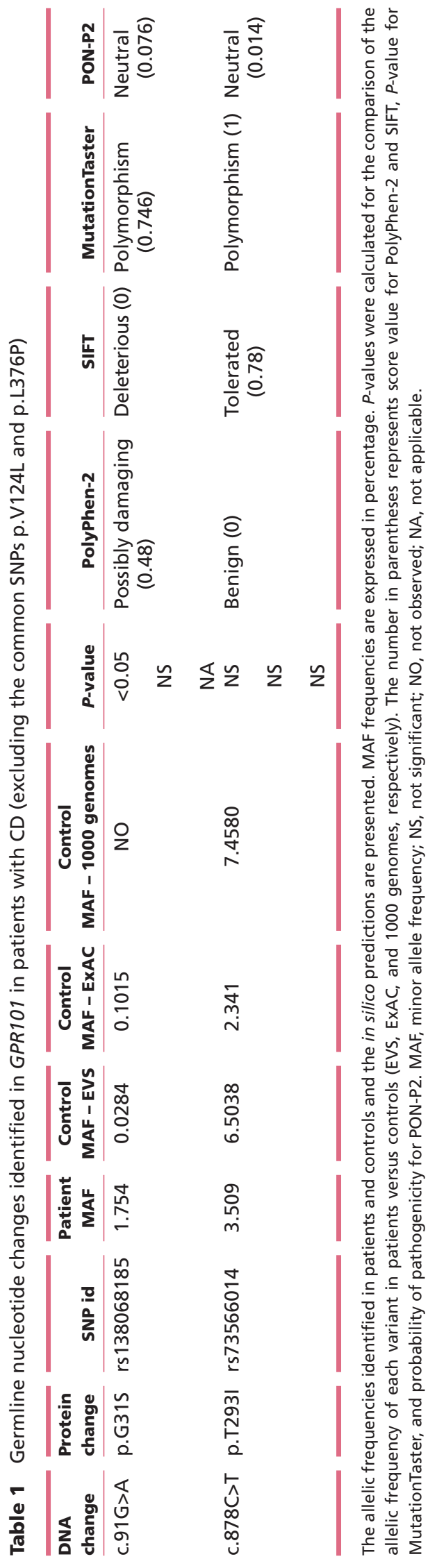

http://erc.endocrinology-journals.org DOI: 10.1530/ERC-16-0091
C 2016 Society for Endocrinology Printed in Great Britain

\section{In silico analysis}

All GPR101 variants were studied in silico, and the allele frequencies observed in our patient population were compared against public databases, including the 1000 Genomes Project (Auton et al. 2015); the Exome Variant Server, NHLBI GO Exome Sequencing Project, Seattle, Washington, USA (http://evs.gs.washington. edu/EVS/) (accessed February 2016); and the Exome Aggregation Consortium, Cambridge, MA, USA (http:// exac.broadinstitute.org) (accessed February 2016). In silico predictions were performed with PON-P2 (Niroula et al. 2015) and Alamut version 2.3 (Interactive Biosoftware, Rouen, France) software packages.

\section{Tissue collection and expression studies}

Pituitary tumor tissue was collected at surgery. Whenever possible, tissue slices were snap-frozen in dry ice; the remainder was fixed in formalin and embedded in paraffin. Five-micrometer-thick sections were stained with hematoxylin-eosin and reticulin for light microscopy. The avidin-biotin peroxidase complex technique was used to stain for ACTH using an antiACTH rabbit polyclonal antibody (Dako; catalog no. A0571) at a working dilution of 1:1000. Some samples were also stained in immunofluorescence for GPR101 (rabbit anti-GPR101, dilution 1:500; SAB4503289, SigmaAldrich) and $A C T H$ (rabbit anti-ACTH, dilution 1:400, Dr A F Parlow, National Institute of Diabetes and Digestive and Kidney Diseases, National Hormone and Peptide Program, Torrance, CA, USA). Immunofluorescence staining for GPR101 was performed using a Tyramide signal amplification kit (T20922, Invitrogen) with a horseradish peroxidase-goat anti-rabbit IgG and Alexa fluor 488 tyramide, according to the manufacturer's instructions. The sections were mounted in Mowiol and visualized under a Leica AF6000 microscope (Leica) at 63× magnification with fixed time of exposure for all samples. The same linear adjustments for brightness, contrast, and color balance have been applied with Adobe Photoshop CS6 to each entire image.

GPR101 and POMC mRNA expression levels were measured by RT-qPCR with TaqMan assay IDs Hs00369662_s1 and Hs01596743_m1, respectively (Applied Biosystems) and normalized on GAPDH (glyceraldehyde3-phosphate dehydrogenase) expression (TaqMan assay ID Hs99999905_m1, Applied Biosystems). TaqMan assays were performed according to the manufacturer's protocol (Applied Biosystems). Briefly, experiments were prepared

Published by Bioscientifica Ltd. 
A

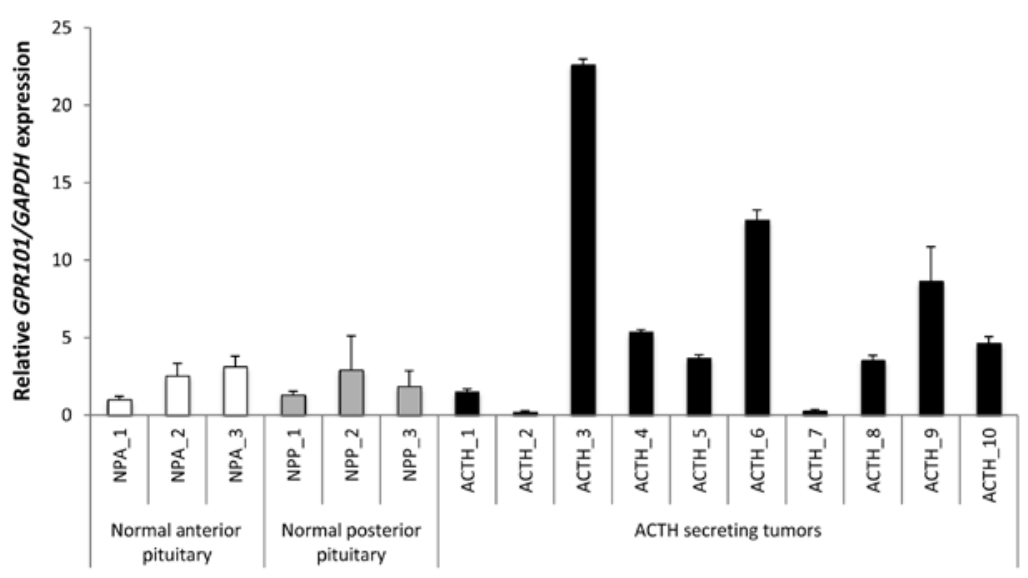

B

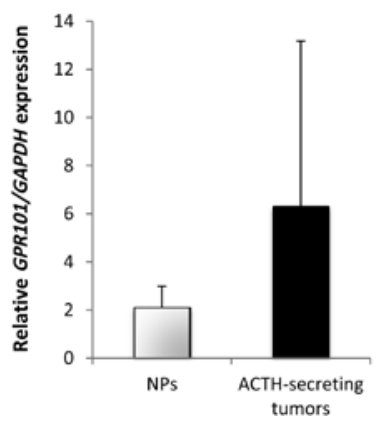

C

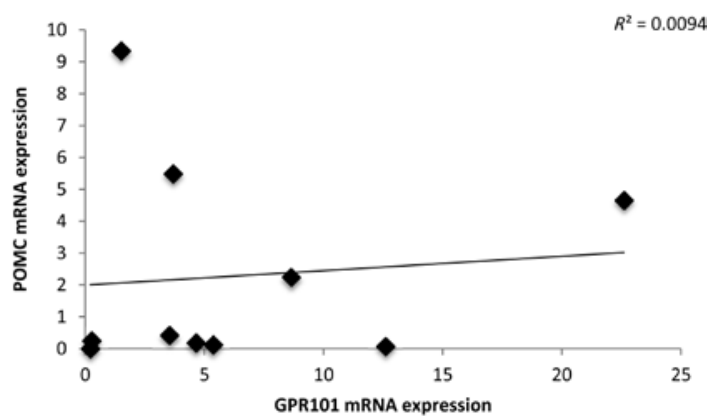

Figure 2

GPR101 and POMC mRNA expression levels in corticotropinomas. None of the analyzed samples harbored GPR101 defects. (A and B) A trend toward higher GPR101 expression in ACTHsecreting tumors can be seen, but it does not reach statistical significance $(P=0.14)$. (C) No correlation between GPR101 and POMC expression levels was observed in ACTH-secreting tumors (Spearman's $R=0.08, P=0.83$ ). Data are expressed as mean \pm S.D. ${ }^{*} P<0.05$. NPA, anterior lobe of normal pituitary; NPP, posterior lobe of normal pituitary; ACTH, ACTH-secreting tumor. in 96-microwell plates and consisted of $20 \mu \mathrm{L}$ reactions containing 20ng of cDNA, 10 $\mu \mathrm{L}$ TaqMan Gene Expression Master Mix (Applied Biosystems, catalog number 4369016), and $1 \mu \mathrm{L}$ each of GPR101 and GAPDH assay mixes. All reactions were performed in triplicate and were run on a ViiA 7 Real-Time PCR System (Applied Biosystems). Thermal cycling conditions were $95^{\circ} \mathrm{C}, 10 \mathrm{~min}$ followed by 40 cycles of $95^{\circ} \mathrm{C}$ for $15 \mathrm{~s}$, and $60^{\circ} \mathrm{C}$ for $1 \mathrm{~min}$. Relative gene expression data were analyzed by $\Delta \Delta \mathrm{C}_{\mathrm{t}}$ method. Data analysis was performed using ViiA 7 software (Applied Biosystems).

\section{Plasmids}

The human GPR101 WT (NM_054021.1) coding sequence cloned into the pCMV-XL5 vector was purchased from Origene (SC120214, Origene, Rockville, MD, USA). The p.G31S variant was introduced into the human GPR101 WT template using the QuikChange Lightning Sitedirected Mutagenesis Kit (210518-5, Agilent Technologies), following the manufacturer's protocol. The following mutagenic primers were used: GPR101-G31S_ F: GAGCGGATGATGCTGTGGGCCAGGCTG; GPR101G31S_R: CAGCCTGGCCCACAGCATCATCCGCTC.

\section{Cell culture}

The rat pituitary somatomammotroph GH3 cell line and the mouse pituitary corticotroph AtT-20 cell line were grown in Dulbecco's modified Eagle's medium (DMEM, high glucose, pyruvate, no glutamine; 10313, Gibco) supplemented with 10\% fetal bovine serum (100106, Gemini Bio Products, West Sacramento, CA, USA) and $1 \%$ antibiotic-antimycotic (15240-062, Gibco) in a humidified atmosphere at $37^{\circ} \mathrm{C}$ with $5 \% \mathrm{CO}_{2}$.

\section{Cell proliferation assay}

GH3 cells were seeded into 96-well plates at a density of $2 \times 10^{4}$ cells per well. After $24 \mathrm{~h}$, cells were starved with DMEM without serum for $16 \mathrm{~h}$ and then transfected with Lipofectamine 2000 (11668030, Invitrogen) according to the manufacturer's protocol, using Opti-MEM I Reduced Serum Medium (31985-070, Gibco) and $125 \mathrm{ng}$ of each vector (human WT GPR101, p.G31S GPR101), alone or in combination. The empty pCMV-XL5 vector was used as a negative control.

AtT-20 cells were plated and transfected following the same protocol, but were not starved, because we

Published by Bioscientifica Ltd 

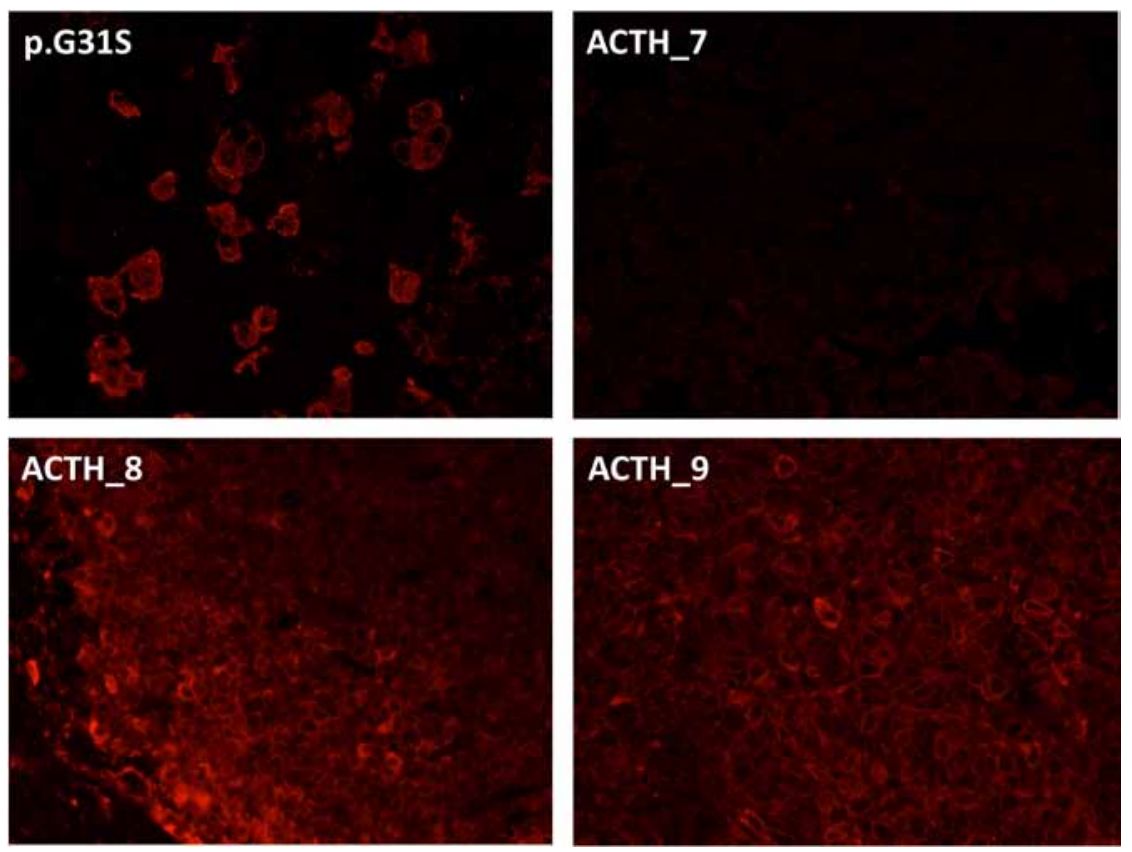

\section{Figure 3}

ACTH immunostaining in corticotroph tumors of four patients with $\mathrm{CD}$. ACTH protein expression (red) of cases ACTH_7, 8, and 9 reflects the POMC mRNA levels shown in Fig. 2C. The tumor of the patient harboring the p.G31S GPR101 variant shows some ACTH-positive sparse cells, as also shown in Fig. 4D.

observed that starvation significantly impacts cell viability. After $24 \mathrm{~h}$ transfection, cell viability and cellular proliferation were assessed for both cell lines with an MTT (3-(4,5-dimethylthiazol-2-yl)-2,5-diphenyltetrazolium bromide)-based assay (Vybrant MTT Cell Proliferation Assay Kit, Invitrogen) as described previously (Trivellin et al. 2014).

\section{CAMP reporter assay}

GH3 and AtT-20 cells were seeded in 12-well plates at a density of $2 \times 10^{5}$ cells per well. After $24 \mathrm{~h}$, GH3 cells only were starved with DMEM without serum for $16 \mathrm{~h}$, and then both cell lines were transfected with Lipofectamine 2000 according to the manufacturer's protocol, using Opti-MEM I Reduced Serum Medium, $1 \mu \mathrm{g}$ of each GPR101 vector (human WT GPR101, p.G31S GPR101), 800 ng of pGL4.29[luc2P/CRE/Hygro] vector containing a cAMP response element that drives the transcription of the luciferase reporter gene (Promega), and $40 \mathrm{ng}$ of the Renilla vector (pRL-SV40, Promega). The empty pCMV-XL5 vector was used as a negative control. At $24 \mathrm{~h}$ after transfection, a subset of cells was treated with $10 \beta \mathrm{M}$ forskolin (F6886, Sigma-Aldrich) for $1 \mathrm{~h}$ and then lysed. Firefly and Renilla luciferase activities were measured consecutively in the same sample using the Dual-Luciferase Reporter Assay System (E1910, Promega) as described previously (Trivellin et al. 2014).

\section{Hormone assays}

GH3 and AtT-20 cells were seeded in 12-well plates and then transfected as reported in the 'cAMP reporter assay' section, using $1 \mu \mathrm{g}$ of each GPR101 vector. At $24 \mathrm{~h}$ after transfection, supernatants were collected and hormone concentration was measured. For GH3 cells, GH secretion was measured using the rat/mouse Growth Hormone ELISA Kit (EZRMGH-45K, EMD Millipore) as described previously (Trivellin et al. 2014). For AtT-20 cells, ACTH secretion was measured using the ACTH (rat, mouse) Chemiluminescent EIA KIT (CEK-001-21, Phoenix Pharmaceuticals, Belmont, CA, USA) following the manufacturer's protocol.

\section{Statistical analyses}

Statistical analysis was performed using StatsDirect software (Addison-Wesley-Longman, Cambridge, UK). Data are presented as the mean \pm s.D. of two to five independent experiments, each performed at least in triplicate. Comparisons were calculated using a two-tailed Student's $t$-test for unpaired data and the Kruskal-Wallis test followed by the Conover-Inman test, as appropriate. A $\chi^{2}$-test was used to compare the allelic frequencies of the variants in patients and controls. Spearman's correlation coefficient by rank was used to compare GPR101 and POMC mRNA expression levels. The data were considered to be significant when $P<0.05$.

Published by Bioscientifica Ltd 

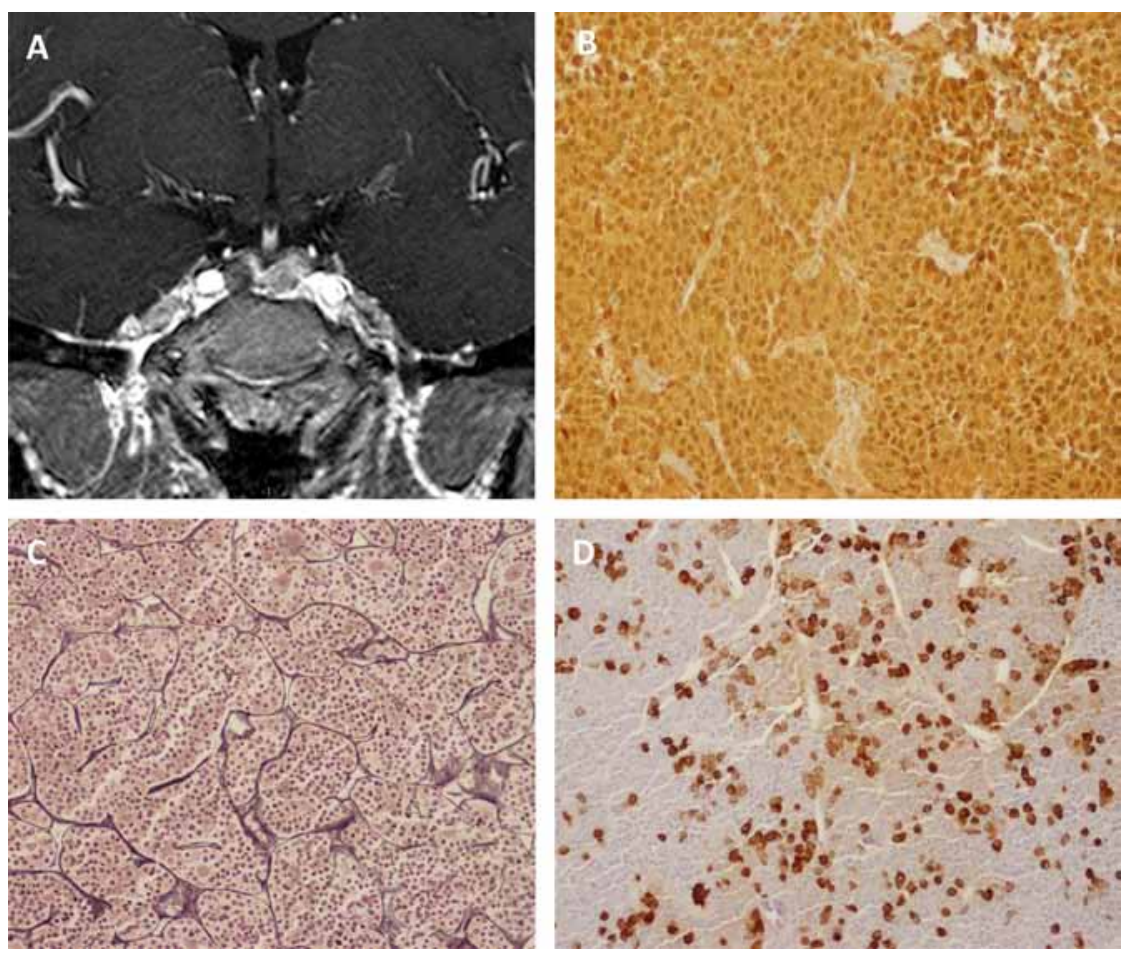

Figure 4

Imaging and histopathological findings for patients with GPR101 variants. Patient with the p.T293I GPR101 variant in homozygosity: (A) There is a round space-occupying lesion in the right half of the pituitary showing decrease enhancement with respect to NP tissue. This abnormality represents the microadenoma that abuts the intracavernous segment of the right internal carotid artery. The bony defect inferior to the adenoma is the result of a prior surgery. (B) ACTH staining of the microadenoma showing diffuse and strong ACTH expression. Patient with the heterozygous p.G31S GPR101 variant: (C) Reticulin staining showing disruption of reticulin network and expanded hyperplastic acini. (D) ACTH staining showing an expression pattern typical of normal anterior pituitary. All three images were taken at $10 \times$ magnification.

\section{Results}

\section{GPR101 sequencing analysis in ACTH-secreting tumors}

Germline DNA from 36 patients with CD (58\% females, mean age at diagnosis: $14.4 \pm 8.13$ years old) was sequenced for GPR101; 32 of these patients have been included in our previous series of pediatric patients with CD (Stratakis et al. 2010, Trivellin et al. 2014). Two common SNPs (p.V124L and p.L376P) were detected in several patients' samples with frequencies comparable to those observed in control subjects, similarly to what we previously reported (Trivellin et al. 2014), and a less common SNP (p.T293I, 5\% allele frequency in controls) was observed in one patient in the homozygote state (Fig. 1). In silico analysis was not supportive for pathogenic function (Table 1). A very rare variant (p.G31S) was detected in another patient in the heterozygote state. Although some in silico programs reported it as benign, others classified it as possibly damaging (Table 1). These patients had classic CD without atypical features (Supplementary Table 1, see section on supplementary data given at the end of this article). GPR101 sequencing was also performed successfully at the somatic level in $33 \mathrm{ACTH}$-secreting tumors; no de novo somatic variants were reported in GPR101.

\section{GPR101-ACTH expression in ACTH-secreting tumors}

We performed RT-qPCR for GPR101 in 10 corticotropinomas and 3 NPs collected at autopsy. Each NP was divided into the anterior and posterior lobes. None of these samples harbored GPR101 mutations. We observed a trend toward higher GPR101 expression in the tumors compared with NPs, with this being particularly evident for three samples (Fig. 2A), but it did not reach statistical significance $(P=0.14$, Fig. $2 \mathrm{~B})$.

We then measured POMC mRNA expression in the tumor samples to determine if there was a correlation with GPR101 mRNA levels. We found no correlation between GPR101 and POMC expression levels (Spearman's $R=0.08$, $P=0.83$, Fig. 2C). ACTH expression in four available tumors was also investigated at the protein level by immunostaining (Fig. 3). ACTH protein expression corresponded well with POMC mRNA levels as shown in Fig. 2C. ACTH expression levels in the patient harboring the p.G31S GPR101 variant were intermediate between those of the other three analyzed tumors; in the patient with the homozygous p.T293I variant it was unremarkable (Figs 3 and 4). GPR101 staining was performed in the same specimens but resulted in nonspecific signal that could be a consequence of tissue collection/ preparation (data not shown). We had successful double labeling with two antibodies raised in rabbit (including GPR101), but it just did not work with these tumor samples.

\section{In vitro functional studies for GPR101 p.G31S variant}

Based on the in silico results and on the very low allele frequency with which the p.G31S variant is reported in

Published by Bioscientifica Ltd 
A

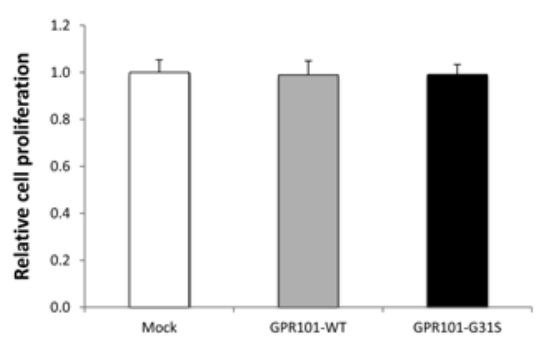

C

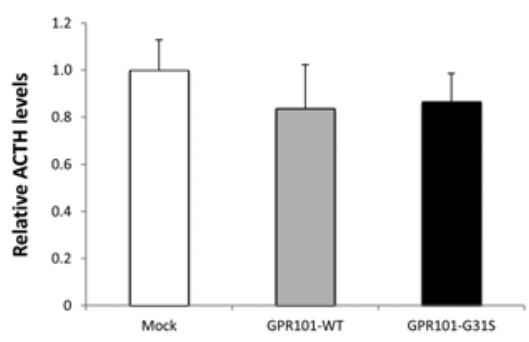

E

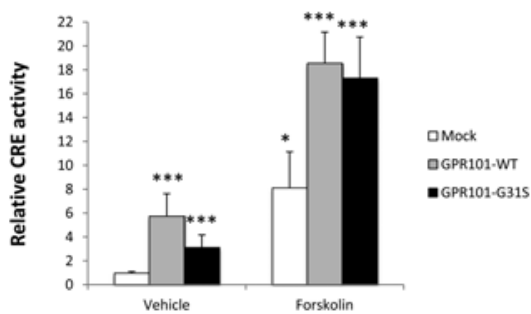

B

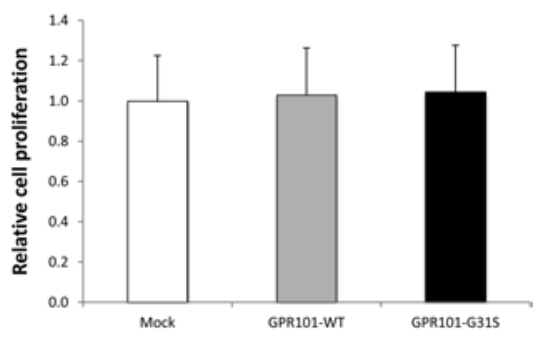

D

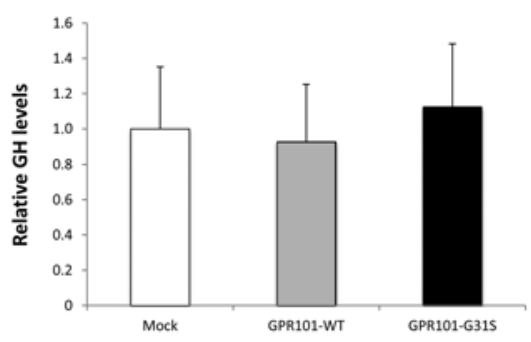

F

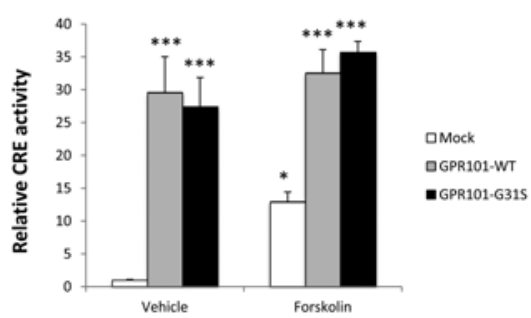

Figure 5

In vitro functional studies in pituitary tumor cell lines. An MTT assay was performed in AtT-20 (A) and GH3 cells (B). No effect of the WT GPR101 nor of the p.G31S variant was observed on cell proliferation. Mouse ACTH (C) and rat GH (D) secretion was measured with specific ELISA assays from AtT-20 and GH3 cell supernatants, respectively. No effect of the WT GPR101 nor of the p.G31S variant was observed on the secretion of both hormones. CAMP pathway activation was measured in AtT-20 (E) and GH3 (F) cells upon GPR101 overexpression. A significant increase in cAMP levels was observed in both cell lines compared with control, but this increase was not different between WT and mutated GPR101. Data are expressed as mean \pm S.D. of two to three independent experiments, each performed in triplicate. ${ }^{*} P<0.05 ; * * * P<0.001$ the population (making it more likely to be pathogenic), we performed in vitro functional studies. An MTT assay was performed in AtT-20 and GH3 cells, but no effect of the variant was observed on cell proliferation in neither cell lines (Fig. 5A and B). Moreover, overexpression of the WT GPR101 construct did not increase cell proliferation in either cell lines, as previously observed (Trivellin et al. 2014). ACTH and GH secretion from, respectively, AtT20 and GH3 cells was also measured after overexpression of the p.G31S variant. No increased secretion of either hormones was observed compared with cells transfected with mock control, neither for WT nor for mutated p.G31S GPR101 (Fig. 5C and D). Activation of the cAMP pathway was measured with a reporter assay in AtT-20 and GH3 cells upon p.G31S overexpression. In both cell lines, a significant increase in cAMP levels was observed compared with mock control $(P<0.001)$; however, this increase was not different from what was seen with the WT GPR101 construct (Fig. 5E and F). In basal conditions, the increase in cAMP activation caused by GPR101 overexpression in AtT-20 cells (Fig. 5E) was lower than that seen in GH3 cells $(P<0.001$, Fig. 5F).
The additional stimulation of the cAMP pathway with forskolin showed a synergistic effect only in AtT-20 cells (Fig. 5E and F).

\section{Discussion}

GPR101 has been previously shown to be expressed in hypothalamic neurons expressing proopiomelanocortin (POMC), the precursor of ACTH (Nilaweera et al. 2007, Bagnol 2010). Moreover, GPR101 was shown to mediate the phosphorylation of epidermal growth factor receptor (EGFR), leading to enhanced cellular migration (Cho-Clark et al. 2014) and invasion (Cho-Clark et al. 2015). EGFR is frequently overexpressed in ACTH-secreting tumors, and the EGFR-mediated pathway is essential for POMC synthesis (Theodoropoulou et al. 2004, Fukuoka et al. 2011). A GPR101 variant, p.E308D, previously observed in some patients with GH-secreting adenomas (Trivellin et al. 2014) was also recently reported in two patients with ACTH-secreting adenomas (Lecoq et al. 2016).

Based on the possible link between GPR101 and the physiology of ACTH-secreting cells, we decided

Published by Bioscientifica Ltd 
to study if GPR101 plays a role in the pathogenesis of corticotropinomas. As nothing is known regarding the expression of the receptor in these tumors, we first measured its expression levels in 10 corticotropinomas and compared them with three NP samples. We did not observe different expression levels of GPR101 between tumors and NP tissues (Fig. 2A and B). Moreover, no correlation with POMC expression levels was observed (Fig. 2C). We then sequenced a series of patients with CD to look for possible GPR101 germline and somatic mutations. In addition to two very common SNPs, two other missense variants (p.G31S and p.T293I) were observed at the germline level (Fig. 1). Both variants have been reported in public databases and in the literature (Trivellin et al. 2014, Castinetti et al. 2016). Although p.T293I is a relatively common variant with a minor allele frequency (MAF) of about 6\% (an average calculated from three public databases, Table 1), p.G31S is a very rare variant, with a MAF of about $0.06 \%$, and was predicted in silico to be possibly damaging. However, functional in vitro studies of this variant did not show an increase in hormone secretion nor in cell proliferation (Fig. 5). We were able to see a significant increase in cAMP pathway activation, compared with controls, but this was not significantly different from that elicited by the WT GPR101 construct (Fig. 5E and F). It is also interesting to note that in basal conditions, the increase in cAMP pathway activation caused by GPR101 overexpression in AtT-20 cells (Fig. 5E) was significantly lower than that seen in GH3 cells (Fig. 5F; Trivellin et al. 2014). Only in the presence of a potent stimulator of the cAMP pathway, GPR101 was able to exert on the AtT-20 cells an effect of similar magnitude to that observed in GH3 cells. These findings suggest that GPR101 may activate the cAMP pathway at different magnitudes in different hormone-secreting cell types. The lower activation of the cAMP pathway in corticotrophs might be in line with some studies, indicating that this pathway does not play a significant pathogenetic role in corticotropinomas (reviewed in (Bertagna 2011)). Therefore, it might be possible that GPR101 activates different intracellular signaling pathways in corticotroph cells than in somatotrophs. It would be interesting to investigate this aspect in future studies, in particular in relation to the p.G31S variant.

In conclusion, in this study we investigated pediatric patients with CD for GPR101 defects but found little to support that this gene might be involved in the pathogenesis of corticotropinomas. The finding of a rare, potentially functional GPR101 variant in one patient with
CD was interesting, but in vitro studies did not support a tumor-inducing role for this sequence change.

\section{Supplementary data}

This is linked to the online version of the paper at http://dx.doi.org/10.1530/ ERC-16-0091.

Declaration of interest

The authors declare that there is no conflict of interest that could be perceived as prejudicing the impartiality of the research reported.

\section{Funding}

This research was supported by the Intramural Research Program of Eunice Kennedy Shriver National Institute of Child Health and Human Development, National Institutes of Health, Bethesda, Maryland, USA; the Fonds d'Investissement pour la Recherche Scientifique of the Centre Hospitalier Universitaire de Liege, University of Liège, Liège, Belgium; and NIH RO3HD078645 and National Science Foundation IOS1052288 grants.

\section{References}

Auton A, Abecasis GR, Altshuler DM, Durbin RM, Abecasis GR, Bentley DR, Chakravarti A, Clark AG, Donnelly P, Eichler EE, et al. 2015 A global reference for human genetic variation. Nature 526 68-74. (doi:10.1038/nature15393)

Bagnol D 2010 Use of gpr101 receptor in methods to identify modulators of hypothalamic proopiomelanocortin (POMC)-derived biologically active peptide secretion useful in the treatment of pomc-derived biologically active peptide-related disorders. US Patent 8142762. (http://www.google.com/patents/US8142762?cl=en).

Bates B, Zhang L, Nawoschik S, Kodangattil S, Tseng E, Kopsco D, Kramer A, Shan Q, Taylor N, Johnson J, et al. 2006 Characterization of Gpr101 expression and G-protein coupling selectivity. Brain Research 1087 1-14. (doi:10.1016/j.brainres.2006.02.123)

Beckers A, Lodish MB, Trivellin G, Rostomyan L, Lee M, Faucz FR, Yuan B, Choong CS, Caberg JH, Verrua E, et al. 2015 X-linked acrogigantism syndrome: clinical profile and therapeutic responses. Endocrine-Related Cancer 22 353-367. (doi:10.1530/ERC-15-0038)

Bertagna X, Raux-Demay MC, Guilhaume B, Girard F \& Luton JP 2011 Pituitary tumors. In The Pituitary, edn 3, p 541. Ed S Melmed. London, UK: Elsevier.

Castinetti F, Daly AF, Stratakis CA, Caberg JH, Castermans E, Trivellin G, Rostomyan L, Saveanu A, Jullien N, Reynaud R, et al. 2016 GPR101 mutations are not a frequent cause of congenital isolated growth hormone deficiency. Hormone and Metabolic Research [in press]. (doi:10.1055/s-0042-100733)

Cho-Clark M, Larco DO, Semsarzadeh NN, Vasta F, Mani SK \& Wu TJ 2014 GnRH-(1-5) transactivates EGFR in Ishikawa human endometrial cells via an orphan $\mathrm{G}$ protein-coupled receptor. Molecular Endocrinology 28 80-98. (doi:10.1210/me.2013-1203)

Cho-Clark M, Larco DO, Zahn BR, Mani SK \& Wu TJ 2015 GnRH-(1-5) activates matrix metallopeptidase- 9 to release epidermal growth factor and promote cellular invasion. Molecular and Cellular Endocrinology 415 114-125. (doi:10.1016/j.mce.2015.08.010)

Daly AF, Lysy PA, Desfilles C, Rostomyan L, Mohamed A, Caberg JH, Raverot V, Castermans E, Marbaix E, Maiter D, et al. 2016 GHRH excess and blockade in X-LAG syndrome. Endocrine-Related Cancer 23 161-170. (doi:10.1530/ERC-15-0478) 
Fukuoka H, Cooper O, Ben-Shlomo A, Mamelak A, Ren SG, Bruyette D \& Melmed S 2011 EGFR as a therapeutic target for human, canine, and mouse ACTH-secreting pituitary adenomas. Journal of Clinical Investigation 121 4712-4721. (doi:10.1172/JCI60417)

Lecoq AL, Bouligand J, Hage M, Cazabat L, Salenave S, Linglart A, Young J, Guiochon-Mantel A, Chanson P \& Kamenický P 2016 Very low frequency of germline GPR101 genetic variation and no biallelic defects with AIP in a large cohort of patients with sporadic pituitary adenomas. European Journal of Endocrinology 174 523-530. (doi:10.1530/EJE-15-1044)

Lee DK, Nguyen T, Lynch KR, Cheng R, Vanti WB, Arkhitko O, Lewis T, Evans JF, George SR \& O'Dowd BF 2001 Discovery and mapping of ten novel G protein-coupled receptor genes. Gene 275 83-91. (doi:10.1016/S0378-1119(01)00651-5)

Newell-Price J 2009 Diagnosis/differential diagnosis of Cushing's syndrome: a review of best practice. Best Practice \& Research Clinical Endocrinology \& Metabolism 23 (Supplement 1) S5-S14. (doi:10.1016/ s1521-690x(09)70003-x)

Nilaweera KN, Ozanne D, Wilson D, Mercer JG, Morgan PJ \& Barrett P $2007 \mathrm{G}$ protein-coupled receptor 101 mRNA expression in the mouse brain: altered expression in the posterior hypothalamus and amygdala by energetic challenges. Journal of Neuroendocrinology 19 34-45. (doi:10.1111/j.1365-2826.2006.01502.x)

Nilaweera KN, Wilson D, Bell L, Mercer JG, Morgan PJ \& Barrett P 2008 $\mathrm{G}$ protein-coupled receptor 101 mRNA expression in supraoptic and paraventricular nuclei in rat hypothalamus is altered by pregnancy and lactation. Brain Research 1193 76-83. (doi:10.1016/j. brainres.2007.11.048

Niroula A, Urolagin S \& Vihinen M 2015 PON-P2: prediction method for fast and reliable identification of harmful variants. PloS ONE $\mathbf{1 0}$ e0117380.
Peverelli E, Mantovani G, Lania AG \& Spada A 2014 cAMP in the pituitary: an old messenger for multiple signals. Journal of Molecular Endocrinology 52 R67-R77. (doi:10.1530/JME-13-0172)

Regard JB, Sato IT \& Coughlin SR 2008 Anatomical profiling of G protein-coupled receptor expression. Cell 135 561-571. (doi:10.1016/j.cell.2008.08.040)

Reincke M, Sbiera S, Hayakawa A, Theodoropoulou M, Osswald A, Beuschlein F, Meitinger T, Mizuno-Yamasaki E, Kawaguchi K, Saeki Y, et al. 2015 Mutations in the deubiquitinase gene USP8 cause Cushing's disease. Nature Genetics 47 31-38.

Stratakis C, Tichomirowa M, Boikos S, Azevedo M, Lodish M, Martari M, Verma S, Daly A, Raygada M, Keil M, et al. 2010 The role of germline AIP, MEN1, PRKAR1A, CDKN1B and CDKN2C mutations in causing pituitary adenomas in a large cohort of children, adolescents, and patients with genetic syndromes. Clinical Genetics 78 457-463.

Theodoropoulou M, Arzberger T, Gruebler Y, Jaffrain-Rea ML, Schlegel J, Schaaf L, Petrangeli E, Losa M, Stalla GK \& Pagotto U 2004 Expression of epidermal growth factor receptor in neoplastic pituitary cells: evidence for a role in corticotropinoma cells. Journal of Endocrinology 183 385-394. (doi:10.1677/joe.1.05616)

Tritos NA \& Biller BM 2014 Cushing's disease. Handbook of Clinical Neurology 124 221-234. (doi:10.1016/B978-0444-59602-4.00015-0)

Trivellin G, Daly AF, Faucz FR, Yuan B, Rostomyan L, Larco DO, Schernthaner-Reiter MH, Szarek E, Leal LF, Caberg JH, et al. 2014 Gigantism and acromegaly due to Xq26 microduplications and GPR101 mutation. New England Journal of Medicine 371 2363-2374. (doi:10.1056/NEJMoa1408028)

Received in final form 22 February 2016

Accepted 7 March 2016

Accepted Preprint published online 9 March 2016
() 2016 Society for Endocrinology Printed in Great Britain
Published by Bioscientifica Ltd 